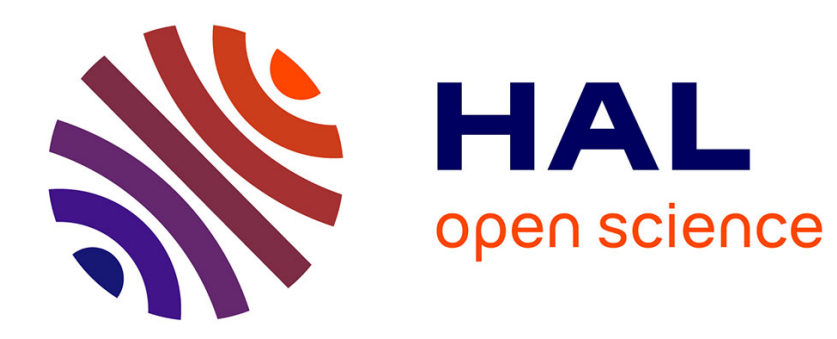

\title{
Some problems for Lowe's Four-Category Ontology Max Kistler
}

\section{To cite this version:}

Max Kistler. Some problems for Lowe's Four-Category Ontology. Analysis, 2004, 64 (2), pp.146-151. ijn_00000538

\section{HAL Id: ijn_00000538 \\ https://hal.science/ijn_00000538}

Submitted on 6 Oct 2004

HAL is a multi-disciplinary open access archive for the deposit and dissemination of scientific research documents, whether they are published or not. The documents may come from teaching and research institutions in France or abroad, or from public or private research centers.
L'archive ouverte pluridisciplinaire HAL, est destinée au dépôt et à la diffusion de documents scientifiques de niveau recherche, publiés ou non, émanant des établissements d'enseignement et de recherche français ou étrangers, des laboratoires publics ou privés. 
conditions under which support fails to transmit to $\mathrm{C}$ is correct; we simply deny that in the voting example (normal) those conditions are in fact satisfied.

If this is right, then Wright's account of why evidential support may fail to transmit across entailment is validated by a Bayesian analysis, just as the proof above suggested at first sight. Where B entails $\mathrm{C}$, then if A supports $\mathrm{B}$ conditionally on $\mathrm{C}$ but not otherwise, it is true that A cannot support $\mathrm{C}$, where support is understood in the usual Bayesian way, as enhancement of prior probability. Wright's distinction between indirect and direct support muddies the waters. Relativizing probabilities to background knowledge obviates the need for the direct/indirect support distinction, allowing us to accept Wright's analysis of the conditions under which transmission failure occurs.

\author{
University of Bristol, \\ 9 Woodland Road, \\ Bristol BS8 1TB, U.K. \\ samir.okasha@bristol.ac.uk
}

\title{
References
}

Wright, C. 1985. Facts and certainty. Proceedings of the British Academy 71: 429-72. Wright, C. 2002. (Anti-)sceptics simple and subtle: G. E. Moore and John McDowell. Philosophy and Phenomenological Research 65: 330-48.

\section{Some problems for Lowe's four-category ontology} MAX KISTLER

In recent work, E. J. Lowe (1998b: Chap. 9, 1998c, 2001, 2002a, 2002b, 2003a) has developed a 'four-category ontology' whose fundamental ontological categories result from two distinctions: between object and property and between particular and universal. In Lowe's metaphysical scheme, inspired by Aristotle's distinction between primary and secondary substances, there are two fundamentally different types of individual objects: particular objects, such as rocks, animals and persons, and universal objects, the most important instances of which are kinds, such as the kind oak trees or the kind gold. Particular objects instantiate their kinds. 


\section{Particular objects}

According to Lowe, an individual ${ }^{1}$ object is an 'entity which bears properties' (2003a: 11), possesses 'determinate identity conditions' (1998b: 181), and has the unity required for making it countable (cf. Lowe 1998a, Lowe 1998 b, chap. 3). Entities satisfying the second but not the third requirement are called 'quasi-individuals' (1998b: 76); ${ }^{2}$ entities satisfying the third but not the second are called 'quasi-objects' (1998a: 197, 1998b: 59, 70).

One problem for Lowe's criterion of objecthood is that it allows entities to switch ontological categories: something can become an object or cease to be an object. Consider Lowe's example of quasi-individuals, parts of (hypothetical) absolutely homogeneous stuff. Such parts do not possess sufficient unity to be countable 'because every such part is infinitely divisible into smaller parts of the same kind of stuff' (1998a: 200; cf. also 1998b: 201). Contrary to its parts, a piece of stuff, i.e. a 'maximal connected part of stuff' (1998a: 200), is countable, hence an object. According to Lowe's criterion, a piece of stuff ceases to be an object when it gets attached to a second piece, thereby ceasing to be a maximal part.

True, Lowe allows 'transubstantiation', an object changing in kind while continuing to exist as an object. 'It appears to be metaphysically possible for an individual living organism to start life as, say, a cat and yet to survive a process of transmutation which turns it into a dog.' (1998b: 186, italics Lowe's; cf. also 1989: 103). However, transubstantiation does not make anything cross the boundaries between fundamental ontological categories.

A second problem for Lowe's account is that he fails to make a convincing case for the existence of quasi-individuals: any amount of stuff, homogeneous or non-homogeneous, such as water and gold, is measurable, hence countable, and should therefore qualify as an object. Counting stuff, contrary to counting more 'organic' substances, ${ }^{3}$ requires an arbitrary unit of measurement. It also requires a 'principle of individuation', allowing us to distinguish different parts, so as not to count them twice over. The space occupied by parts of stuff can serve as such a principle. Lowe's argument that 'parts of space themselves, like parts of stuff, very arguably lack a principle of individuation' (1998a: 201), can be overcome. There are objects such as persons or rocks, which are situated in space and whose individuation poses no problems (first step). These objects can be used as landmarks to ascribe individual identity to points in space (second step). In a third

${ }^{1}$ I shall henceforth omit the qualifier 'individual', using the term 'object' as meaning 'individual object'.

2 In Lowe 2003b, he calls such entities 'dividuals'.

3 Being organic means having an 'internal principle of unity' (Lowe 1998b: 15). 
step, parts of stuff (whether homogeneous or not) can be individuated by indicating their position relative to those points. Lowe still owes us an argument for his thesis that countability is a non-trivial criterion of objecthood.

The problem that Lowe's criterion allows entities to switch ontological categories also arises for 'quasi-objects', such as quantum particles, which are Lowe's 'example[s] of countability without determinate identity' (1998a: 194; cf. 1998b: 62). The two electrons in the electron shell of a helium atom are countable, but not objects because they lack individual identity: it is firmly established in physics that they cannot be taken to be individuals which could be described, as if they were bearing a tag. However, they become objects when they leave the atomic shell, for only interacting indistinguishable particles lack individual identity. Take photons, which, within a system of many photons, lack individual identity. However, a single photon can become an object by leaving the interacting system: it can even be consciously perceived. Perceived, it is certainly one; it is also an individual: I can distinguish it from others by such a description as 'the photon I just perceived to my left'.

Let us try to modify Lowe's criterion so as to avoid having entities change ontological categories. Maybe, to be an object, an entity must sometimes, or always, have unity and individual identity. Lowe himself suggests this when he says that electrons are 'not always determinately identifiable' (1998a: 197, 1998b: 70). However, this would make objecthood depend on contingent circumstances. This suggests that we rather need a modal qualification. Maybe, in order for an entity to be an object it must be possible for it to have unity and individual identity. That would make electrons and photons objects, and therefore match the intuition that a perceived individual photon is an object. However, we cannot really say of an electron in an entangled quantum state that it has possibly determinate identity (because it is possible that it leaves the entangled state): the pronoun 'it' has no definite reference in this situation. As a last resort, we may consider requiring an object to have determinate identity and unity necessarily. However, this is too strong, for two reasons. First, it disqualifies quantum particles as objects, making them only 'quasi-objects'. But we have seen that perceived single photons are objects. Second, against Lowe's stated aim, it disqualifies all pieces of stuff from being objects. For no piece of stuff is necessarily maximal: for any such piece, it is possible to join it to another piece, thereby making of those parts a whole new piece.

\section{Kinds}

Besides particular objects, Lowe's ontological scheme contains 'universal objects', whose main representatives are kinds. ${ }^{4}$ Lowe's thesis that kinds

${ }^{4}$ Numbers also fall into this category. Cf. 1998b: Chap. 10.7. 
are objects presupposes that kinds are (1) genuine property bearers (cf. 1989: 148, 2002b: 143), (2) have determinate identity conditions (cf. 1989: 101-4) and are countable, and (3) have ontological independence (cf. 1989: 162-63). However, it is doubtful whether kinds meet these requirements.

(1) Kinds do not bear properties in a more genuine sense than (firstorder) properties. Being numerous or rare may seem to be clear cases of properties of kinds. But Lowe cannot accept them, for he explicitly denies that instantiation is a genuine property, or rather, a genuine relation between the kind and its instances. He recommends calling it a 'relationship' instead. ${ }^{5}$ If the number of times a property is instantiated does not count as a (second-order) property of that property, it cannot count as a property of a kind either. Lowe's own examples of properties of kinds do not seem to be properties of kinds at all, but rather properties of the members of the kind. Lowe sometimes says that kinds 'possess' properties: laws of nature, e.g. that common salt is water-soluble, consist 'in the possession by such kinds of certain properties' (2001: 13; cf. also 2002b: 145-46 and 2003a: 19). But the property of being water-soluble can only be attributed sensibly to particular samples of salt, not the kind: only the former but not the latter can dissolve in water. In other places, he speaks of kinds 'being characterized by' properties, rather than possessing or bearing them. For example, gold is 'a kind of stuff, which is characterized by many non-substantial universals' (2002a: 232), such as being constituted by atoms with the atomic number 79 . However, being characterized by a property is very different from bearing it. If being constituted by atoms with the atomic number 79 characterizes being gold, this is because the former property is a constitutive part of the latter, complex property. ${ }^{6}$

(2) It is disputed whether biological species, which appear to be paradigmatic kinds, have a real essence providing an absolute basis for counting them. Against that idea, Dupré (1981) shows that there is no unique and universally applicable concept of biological species. 1) Morphological and genetic similarity among individuals is neither necessary nor sufficient for their belonging to a common species. 2) The 'biological species concept', the capacity to produce fertile offspring, does not apply univer-

${ }^{5}$ Cf. 2002a: 236 and 2002b: 140-41. Lowe argues, against Armstrong in particular, that properties do not themselves have properties in the sense in which fundamentallevel objects have properties, and that therefore the fact that properties seem to have (second-order) properties provides no reason to consider them as (second-order) objects.

6 With Frege, one might say that 'gold is composed of atoms with atomic number 79' expresses a relation of subordination between properties, and that the former is a 'character' (Merkmal, Frege, 1987: 86, \$53) of the latter. Of course, Frege himself speaks of concepts rather than properties. 
sally, but only to sexual species. 3) According to the evolutionary concept of species, they correspond to branches of a unique phylogenetic tree. But first, constructing the tree presupposes possessing a criterion of specieshood, in order to be able to decide where to situate the branching-off points. Second, there are biologically real ${ }^{7}$ species, e.g. parasites, that crossclassify the phylogenetic tree. Among parasites, fleas are insects, but tapeworms are not. ${ }^{8}$ This suggests that there is something interest-relative and non-absolute in our species concept. In Locke's terminology, the essences of biological species are nominal rather than real. Therefore, species do not have the intrinsic unity that would make them intrinsically, or absolutely, countable.

Lowe's answer to this kind of argument has been that it concerns the biological species concept, but not the metaphysical notion of a kind (cf. (1998b: 185, n.; also 53, 187). But there seem to be only two ways of determining criteria fixing the identity and unity of a kind: either one relies on the natural sciences studying those kinds or one relies on psychology (or linguistics) to find out about our naive classifications. ${ }^{9}$ In both cases, the identity of kinds turns out to be relative to us, and therefore not absolute. Hence, kinds do not have the unity Lowe requires to consider them as objects.

(3) With respect to ontological independence, kinds do not seem to be better off than (other) properties. Just as properties, kinds come into being with the first individual instantiating them. One reason one might give for thinking that particular objects and kinds are equally fundamental (and thus ontologically independent from each other), is that particular objects,

7 According to Mill, a kind is 'real' if there is an inexhaustible number of things to be found out about it. Cf. Mill 1843, I, 7, $\mathbb{4}$ : 79; and IV, 7, $\$ 5$ and Hacking 1993. Having more properties than those explicitly expressed in any finite description is also part of Lowe's concept of a kind: 'There is, in principle, no finite limit to the number of such characteristics nomically tied to the nature of gold' (Lowe 2002a: 232).

${ }^{8}$ Cf. Khalidi 1993, 1998. This shows that there is no unique taxonomic hierarchy in which each individual belongs only to one kind at a given level. It also suggests that classification in kinds is interest-relative, which would show that kinds do not possess any inherent or absolute criterion of identity giving them intrinsic unity. Rather, distinguishing and counting species resembles distinguishing and counting parts of stuff: first we decide to cut up the set of all animals or plants (the stuff) according to a criterion chosen according to our practical interests. The resulting kinds (parts of stuff) owe their countability to that criterion.

9 One of Lowe's main reasons to postulate kinds is that they are required for grounding laws of nature. Cf. Lowe 2001. Metaphysics should not be satisfied with a concept of laws of nature that does not fit scientific laws. But if laws are scientific laws and kinds are the bearers of laws, the metaphysical concept of kind had better fit scientific kinds. 
e.g. plants, essentially belong to their kinds: 'It is true of any particular oak tree that it could not have failed to be an oak tree' (Lowe 2002c: 113). This would imply that individuals depend on the kinds they instantiate as much as kinds depend on the individuals instantiating them. However, it is incompatible with Lowe's thesis that transubstantiation is conceivable. If a particular object can change in kind, then kinds are not, after all, as ontologically fundamental as particular objects, for then a particular oak tree could exist, even if the kind oak tree does not exist, say because all oak trees have been transmuted into maple trees. Within an Aristotelian scheme, the kind ceases to exist with its last instance. The ontological dependency of kinds on objects instantiating them pleads for putting kinds in the ontological category of properties, not in that of objects. ${ }^{10}$

Université Paris X-Nanterre and Institut Jean Nicod, 1bis, av. Lowendal 75007 Paris, France kistler@ehess.fr

\section{References}

Dupré, J. 1991. Natural kinds and biological taxa. Philosophical Review 90: 66-90.

Frege, G. 1987. Grundlagen der Arithmetik. Stuttgart: Philipp Reclam Jun.

Hacking, I. 1993. Working in a new world: the taxonomic solution. In World Changes: Thomas Kubn and the Nature of Science, ed. P. Horwich, 275-310. Cambridge, Mass.: MIT Press.

Khalidi, M. A. 1993. Carving nature at the joints. Philosophy of Science 60: 100-113.

Khalidi, M. A. 1998. Natural kinds and crosscutting categories. Journal of Philosophy 95: 33-50.

Lowe, E. J. 1998a. Entity, identity and unity. Erkenntnis 48: 191-208.

Lowe, E. J. 1998b. The Possibility of Metaphysics. Oxford: Clarendon Press.

Lowe, E. J. 1998c. Form without matter. Ratio (new series) 11: 214-34.

Lowe, E. J. 2001. Dispositions and laws. Metaphysica 2: 5-23.

Lowe, E. J. 2002a. A defence of the four-category ontology. In Argument und Analyse, ed. C. Moulines and K. Niebergall, 225-40. Paderborn: Mentis.

Lowe, E. J. 2002b. Properties, modes, and universals. The Modern Schoolman 74: 137-50.

Lowe, E. J. 2002c. A Survey of Metaphysics. Oxford: Oxford University Press.

Lowe, E. J. 2003a. Recent advances in metaphysics. Facta philosophica 5: 3-24.

Lowe, E. J. 2003b. Identity, individuality, and unity. Philosophy 78: 321-36.

Mill, J. S. 1843. A System of Logic, Ratiocinative and Inductive. London: Parker. Reprint of the 1891 edition, Honolulu, Hawaii: University Press of the Pacific, 2002.

${ }^{10}$ For helpful comments I am indebted to E. J. Lowe, Jérôme Dokic, Joan Cullen, an anonymous referee for Analysis, and my auditors in Paris, where I presented an earlier version of this paper. 